\title{
Use of Raltegravir in HIV-Infected Pregnant Women: A Case Series and Review of the Literature
}

\author{
Milena M McLaughlin ${ }^{1,2}$, Audrey Galal ${ }^{2}$, Jeannie Ong ${ }^{2}$ and Minh Dinh ${ }^{3^{*}}$ \\ ${ }^{1}$ Midwestern University Chicago College of Pharmacy, Downers Grove, IL, USA \\ ${ }^{2}$ Department of Pharmacy, Northwestern Memorial Hospital, Chicago, IL, USA \\ ${ }^{3}$ Northwestern University, Division of Infectious Diseases, Chicago, IL, USA
}

"Corresponding author: Minh H Dinh, MD, Assistant Professor, Division of Infectious Diseases, Northwestern Medicine, 303 E Superior St., Lurie 9-141, Chicago, IL 60611, USA, Tel: (312) 503-1973; Fax: (312) 908-2528; E-mail: m-dinh@northwestern.edu

Received date: September 17, 2014; Accepted date: November 24, 2014; Published date: November 28, 2014

Copyright: (c) 2014 McLaughlin MM, et al. This is an open-access article distributed under the terms of the Creative Commons Attribution License, which permits unrestricted use, distribution, and reproduction in any medium, provided the original author and source are credited.

\begin{abstract}
Objective: To evaluate the safety and tolerability of RAL therapy and the rapidity with which RAL decreases viral load in HIV-infected pregnant women.

Methods: Women were considered for inclusion in the study if they were HIV-seropositive, $\geq 18$ years of age, and received RAL during pregnancy. HIV viral load, CD4 count (absolute), pregnancy demographics, antiretroviral regimens, adverse events, liver function enzymes, and APGAR scores were collected.

Results: Eight HIV-infected RAL-naïve pregnant women presented between 6 to 39.4 weeks gestational age with a median RNA viral load of 41,083 copies $/ \mathrm{mL}$ at the initiation of RAL. From the initiation of RAL until delivery, the median decline in RNA viral load was $1.60 \mathrm{log}$. At delivery, two patients reached $<48 \mathrm{copies} / \mathrm{mL}$ and two had $<500$ copies $/ \mathrm{mL}$. The median RNA viral load at delivery was 911 copies $/ \mathrm{mL}$. No adverse events in the mother or neonate due to RAL therapy were noted during this study.
\end{abstract}

Conclusions: These results support the safe and efficacious addition of RAL to HAART regimen to decrease RNA viral load late in pregnancy if a patient is not yet virologically suppressed. Further prospective study is needed.

Keywords: Raltegravir; RAL; HIV; Pregnancy; Antiretroviral; Mother-to-child transmission; Perinatal transmission

\section{Introduction}

The rate of perinatal transmission of the human immunodeficiency virus (HIV) in the United States has decreased to $2 \%$ with the implementation of Pediatric AIDS Clinical Trial Group Protocol 076 (PACT076) treatment guidelines encouraging measures such as routine HIV counseling and testing and antiretroviral (ARV) prophylaxis $[1,2]$. Current Department of Health and Human Services (DHHS) guidelines recommend starting a combination of Highly Active Antiretroviral Therapy (HAART) early in pregnancy to decrease the risk of perinatal transmission. Sustaining an undetectable viral load with successful ARV regimen is of the utmost importance while also considering the safety of each ARV agent. Protease inhibitor (PI)-containing regimens, including ritonavir-boosted atazanavir or ritonavir-boosted lopinavir, are two of the recommended therapies due to existing data for safe use [1].

Raltegravir (RAL) is the first integrase strand transfer inhibitor approved by the FDA in 2007 and is classified as FDA Pregnancy Category C [3]. It is considered one of the preferred initial therapies for the treatment of HIV in adults and adolescents by the DHHS guidelines [3]. RAL demonstrates a rapid reduction of viral load [4-7] due to its antiretroviral mechanism targeting a later stage in the cell- life cycle [8]. For this reason, RAL has also been used to reduce transmission risk during emergency surgical procedures [9].

Current DHHS guidelines recommend the use of RAL in pregnant women as an alternative agent only in special circumstances when preferred and other alternative agents cannot be used. This recommendation is based on limited pharmacokinetic and safety data in pregnancy, particularly when drug interactions with PI-containing regimens are a concern [1]. The guidelines do not recommend the use of RAL in the case of viral suppression failure presented late in pregnancy, due to the risk of developing ARV resistance [1]. In some cases, patients presenting with elevated viral loads late in pregnancy are due to non-adherence, multi-drug resistance (MDR), or new HIV diagnosis potentially making the need for a twice daily regimen unattractive to clinicians.

Practitioners are increasingly using RAL due to its unique characteristics such as overall safety and rapid decrease in viral load [10-18]. Due to an increasing number of case reports on the use of RAL in HIV-seropositive pregnant women, practitioners may choose to use RAL when other medications are not well-tolerated or unable to rapidly decrease viral load before delivery. We aim to further support the efficacy and safety of RAL in HIV seropositive (+) pregnant women and promote its use in this special population. The objective of this study is to evaluate the safety and tolerability of RAL therapy and 
the rapidity with which RAL decreases viral load in pregnant women infected with HIV.

\section{Methods}

Women were considered for inclusion in the study if they were HIV-seropositive, $\geq 18$ years of age, and received RAL during pregnancy. HIV viral load, CD4 count (absolute), pregnancy demographics, antiretroviral regimens, adverse events, liver function enzymes, and APGAR scores were collected. HIV viral load monitoring was performed at the infectious disease physician's discretion based on patient specific factors. The Northwestern University and Midwestern University Institutional Review Boards approved this study.

\section{Results}

Eight HIV-infected pregnant women meeting the study inclusion criteria presented between 6 and 39.4 weeks gestational age. In seven cases, RAL was added to decrease RNA viral load over a median of 6 days before delivery; in one case, RAL was used in lieu of ritonavirboosted lopinavir due to presumed toxicity from the protease inhibitors 133 days prior to delivery. Four patients were newly diagnosed with HIV during pregnancy and were ARV naïve. All patients were RAL naïve.

In the seven cases where RAL was added to a standard HAART regimen, the regimens were emtricitabine+tenofovir+lopinivir/ ritonavir+RAL $\quad(n=4)$, lamivudine+zidovudine+lopinivir/ritonavir + RAL $(n=1)$, lamivudine+zidovudine+RAL $(n=1)$ and emtricitabine +tenofovir+atazanavir/ritonavir+RAL $(\mathrm{n}=1)$. The other subject's regimen was emtricitabine+tenofovir+RAL. Raltegravir was added to seven patients' regimen for rapid virological suppression and to one patient due to transaminitis from lopinavir/ritonavir.

The median age of the eight subjects was 32.5 years (range 21-41). Four subjects were newly diagnosed during the pregnancy, and the other four were diagnosed 3, 6, 7, and 21 (congenitally acquired) years prior (Table 1). The patients had a median history of 3.5 gestations. The patients' median viral load at initiation of RAL was 41,083 copies/mL (range 201-351,321). Three patients had $<10,000$ copies/mL, four had between 10,000 and 100,000 copies/mL, and one had over 100,000 copies/mL at initiation of RAL (Table 1).

\begin{tabular}{|c|c|c|c|c|c|c|c|}
\hline $\begin{array}{l}\text { Gestational age at } \\
\text { RAL initiation } \\
\text { (weeks, days) }\end{array}$ & $\begin{array}{l}\text { Reason for } \\
\text { Raltegravir Use }\end{array}$ & $\begin{array}{l}\text { VL at RAL } \\
\text { initiation } \\
\text { (copies } / \mathrm{mL} \text { ) }\end{array}$ & $\begin{array}{l}\text { ARV drugs } \\
\text { during pregnancy }\end{array}$ & $\begin{array}{l}\text { Gestational age at } \\
\text { delivery (weeks, } \\
\text { days) }\end{array}$ & $\begin{array}{l}\text { Exposure to } \\
\text { RAL (days) }\end{array}$ & $\begin{array}{l}\mathrm{VL} \text { at delivery } \\
\text { (copies/mL) }\end{array}$ & $\begin{array}{l}\text { Decline of VL } \\
\text { (log) from RAL } \\
\text { initiation to } \\
\text { delivery }\end{array}$ \\
\hline 38,4 & $\begin{array}{l}\text { Rapid viral } \\
\text { suppression }\end{array}$ & 5,613 & $\begin{array}{l}\text { FTC+TDF+ATV/r } \\
+ \text { RAL }\end{array}$ & 39,3 & 6 & $<20$ & 2.45 \\
\hline 38,4 & $\begin{array}{l}\text { Rapid viral } \\
\text { suppression }\end{array}$ & 96,557 & $\begin{array}{l}\text { FTC+TDF+LPV/r } \\
+ \text { RAL }\end{array}$ & 37,3 & 6 & 30,84 & 1.50 \\
\hline 37,5 & $\begin{array}{l}\text { Rapid viral } \\
\text { suppression }\end{array}$ & 351,321 & $\begin{array}{l}\text { ZVD+3TC+LPV/r } \\
+R A L\end{array}$ & 38,6 & 8 & 7,074 & 1.70 \\
\hline 21,1 & $\begin{array}{l}\text { Transaminitis from } \\
\text { LPV/r }\end{array}$ & 20,670 & $\mathrm{FTC}+\mathrm{TDF}+\mathrm{RAL}$ & 40,1 & 133 & $-^{*}$ & 3.01 \\
\hline 31,1 & $\begin{array}{l}\text { Rapid viral } \\
\text { suppression }\end{array}$ & 61,496 & $Z V D+3 T C+R A L$ & 38,1 & 49 & 911 & 1.83 \\
\hline 39,6 & $\begin{array}{l}\text { Rapid viral } \\
\text { suppression }\end{array}$ & 71,660 & $\begin{array}{l}\text { FTC+TDF+ LPV/r } \\
+ \text { RAL }\end{array}$ & 40,1 & 2 & 13,717 & 0.72 \\
\hline 33,3 & $\begin{array}{l}\text { Rapid viral } \\
\text { suppression }\end{array}$ & 201 & $\begin{array}{l}\text { FTC+TDF+ LPV/r } \\
+ \text { RAL }\end{array}$ & 34,1 & 5 & 66 & 0.48 \\
\hline 35,0 & $\begin{array}{l}\text { Rapid viral } \\
\text { suppression }\end{array}$ & 321 & $\begin{array}{l}\text { FTC+TDF+LPV/r } \\
+ \text { RAL }\end{array}$ & 36,2 & 9 & 26 & 1.09 \\
\hline
\end{tabular}

Table 1: ${ }^{\star}$ Viral load not reported at delivery- viral load $<20$ at 21 days prior and 49 days after delivery.

The median gestational age at delivery was 38.4 weeks (range 34.1-40.1) and two of the deliveries were preterm (34 and 36 weeks). Among six subjects, the median time of exposure to RAL prior to delivery was 7 days (range 2-133) (Table 1). Two subjects were exposed at 49 and 133 days, respectively. From the initiation of RAL until delivery, there was a median decline in viral load of $-1.60 \mathrm{log}$ (range $0.48-3.01$ ). Two subjects reached $<48$ copies $/ \mathrm{mL}$ at delivery and two had viral loads of less than 500 copies $/ \mathrm{ml}$. The median viral load at delivery was 911 copies/ml (range $<20-13,717, \mathrm{n}=7$ ). The delivery method for 5 patients was cesarean section (due to high viral load) and 3 patients underwent vaginal delivery (viral loads $<20,66$, and 26 for vaginal births). The median birth weight of the neonate was $3.13 \mathrm{~kg}$ (range 2.21-3.70). The median APGAR score was 8 (range 7-9) and 9 for 1- and 5-minute evaluations, respectively. No significant adverse events attributed to RAL were reported of the mother or neonate that warranted discontinuation of RAL.

\section{Discussion}

Several previous case reports and case series are consistent with the current study in support of safe and efficacious use of RAL in pregnancy. These reports have shown a rapid decrease in RNA viral load during pregnancy [10-18] and good placental transfer [14,18-20]. Other studies have indicated that RAL has less protein binding [21] 
and a higher penetration in the genital tract secretions than PIs [22] suggesting favorable pharmacokinetics. There is a potential for reduced neonatal clearance, possibly due to decreased neonatal uridine 5'-diphospho-glucuronosyltransferase (UGT) enzyme [14]; however, no significant adverse effects in the mother or fetus due to RAL have been reported in these studies.

RAL has been shown to be more efficacious than placebo to increase viral suppression when added to HAART therapy in the setting of MDR [23]. One patient in our study who was not virologically suppressed was suspected to have MDR, and was successfully suppressed after the addition of RAL to her therapy. RAL has also been shown to have less adverse events and better tolerability in patients than the use of PIs. One study by Cao showed RAL to be less hepatotoxic than PIs and may prevent HIV PI-induced dysregulation of lipid metabolism when added to therapy [24]. Two patients in our study had experienced elevated liver function tests and received RAL in lieu of their previous PI with improvements in liver function.

Further supporting infant safety with the use of RAL in pregnancy, teratogenicity appears to be significantly lower than that of PIs according to the Antiretroviral Pregnancy Registry published through July 2013. The number of birth defects occurring with exposure to any ritonavir-containing regimen in the $1^{\text {st }}$ and $2^{\text {nd }}$ or $3^{\text {rd }}$ trimesters were 2.3 and $2.9 \%$, respectively. Birth defects occurring with exposure to any RAL-containing regimen in the $1^{\text {st }}$ and $2^{\text {nd }}$ or $3^{\text {rd }}$ trimesters were 0.02 and $0.05 \%$, respectively [25]. This is clinically significant for the promotion of RAL use in HIV-infected pregnant women.

\section{Limitations}

Similar to prior published literature on the safety and efficacy of RAL in pregnancy, our study is limited by sample size. It is difficult to isolate the change in RNA viral load specifically attributable to RAL since our subjects were on various ARV regimens. Subjects had various lengths of exposure to RAL, ranging from 1 day to 8 months with a short median time of RAL of 7 days. Our study is also limited due to the lack of maternal and neonatal drug serum concentration data. Serum concentration data would allow better understanding of the pharmacokinetics properties of RAL. Future studies on the use of RAL in pregnancy would be improved by a larger sample of patients and obtaining drug serum concentration data. Future directions should also focus on the use of a once daily integrase inhibitor.

\section{Conclusion}

In this study, the average decrease in viral load with the addition of RAL was $1.60 \mathrm{log}$. No adverse events in the mother or neonate due to RAL therapy were noted. These results support the safe and efficacious addition of RAL to HAART regimen to decrease RNA viral load late in pregnancy if a patient is not yet virologically suppressed. These results may also suggest that RAL is a potential option when other therapies are not tolerated due to toxicities. Further prospective study with a larger population is warranted.

\section{References}

1. http://aidsinfo.nih.gov/contentfiles/lvguidelines/PerinatalGL.pdf

2. Rakhmanina N, Phelps BR (2012) Pharmacotherapy of pediatric HIV infection. Pediatr Clin North Am 59: 1093-1115.

\section{3. http://aidsinfo.nih.gov/contentfiles/lvguidelines/} AdultandAdolescentGL.pdf

4. Delaugerre C, Charreau I, Braun J, NereM, Castro ND, et al. (2010) Time course of total HIV-1 DNA and 2-long-terminal repeat circles in patients with controlled plasma viremia switching to a raltegravir-containing regimen. AIDS 24: 2391-2395.

5. Gotuzzo E, Markowitz M, Ratanasuwan W, Smith G, Prada G, et al. (2012) Sustained efficacy and safety of raltegravir after 5 years of combination antiretroviral therapy as initial treatment of HIV-1 infection: final results of a randomized, controlled, phase II study (Protocol 004). J Acquir Immune Defic Syndr 61: 73-77.

6. Lennox JL, Dejesus E, Berger DS, Lazzarin A, Pollard RB, et al. Raltegravir versus Efavirenz regimens in treatment-naive HIV-1-infected patients: 96-week efficacy, durability, subgroup, safety, and metabolic analyses. J Acquir Immune Defic Syndr 55: 39-48.

7. Markowitz M, Morales-Ramirez JO, Nguyen BY, Kovacs CM, Steigbigel RT, et al. (2006) Antiretroviral activity, pharmacokinetics, and tolerability of MK-0518, a novel inhibitor of HIV-1 integrase, dosed as monotherapy for 10 days in treatment-naive HIV-1-infected individuals. J Acquir Immune Defic Syndr 43: 509-515.

8. Sedaghat AR, Dinoso JB, Shen L, Wilke CO, Siliciano RF (2008) Decay dynamics of HIV-1 depend on the inhibited stages of the viral life cycle. Proc Natl Acad Sci U S A 105: 4832-4837.

9. Papendorp SG, van den Berk GE (2009) Preoperative use of raltegravircontaining regimen as induction therapy: very rapid decline of HIV-1 viral load. AIDS 23: 739.

10. Cha A, Shaikh R, Williams S, Berkowitz LL (2013) Rapid reduction in HIV viral load in late pregnancy with raltegravir: a case report. J Int Assoc Provid AIDS Care 12: 312-314.

11. Hegazi A, Hay P (2013) HIV seroconversion in the third trimester of pregnancy: using raltegravir to prevent mother-to-child transmission. Int J STD AIDS 24: 245-246.

12. Hegazi A, Mc Keown D, Doerholt K, Donaghy S, Sadiq ST, et al. (2012) Raltegravir in the prevention of mother-to-child transmission of HIV-1: effective transplacental transfer and delayed plasma clearance observed in preterm neonates. AIDS 26: 2421-2423.

13. Jaworsky D, Thompson C, Yudin MH, Bitnun A, Brophy J, et al. (2010) Use of newer antiretroviral agents, darunavir and etravirine with or without raltegravir, in pregnancy: a report of two cases. Antivir Ther 15: 677-680.

14. McKeown DA, Rosenvinge M, Donaghy S, Sharland M, Holt DW, et al. (2010) High neonatal concentrations of raltegravir following transplacental transfer in HIV-1 positive pregnant women. AIDS 24: 2416-2418.

15. Nóbrega I, Travassos AG, Haguihara T, Amorim F, Brites C (2013) Short communication: Use of raltegravir in late-presenting $\mathrm{HIV}$-infected pregnant women. AIDS Res Hum Retroviruses 29: 1451-1454.

16. Pinnetti C, Baroncelli S, Villani P, Fantoni M, Tozzi V, et al. (2010) Rapid HIV-RNA decline following addition of raltegravir and tenofovir to ongoing highly active antiretroviral therapy in a woman presenting with high-level HIV viraemia at week 38 of pregnancy. J Antimicrob Chemother 65: 2050-2052.

17. Taylor N, Touzeau V, Geit M, Gisinger M, Egle A, et al. (2011) Raltegravir in pregnancy: a case series presentation. Int J STD AIDS 22: 358-360.

18. Westling K, Pettersson K, Kaldma A, Navér L (2012) Rapid decline in HIV viral load when introducing raltegravir-containing antiretroviral treatment late in pregnancy. AIDS Patient Care STDS 26: 714-717.

19. Best BM (2010) "Raltegravir pharmacokinetics during pregnancy". 50th Interscience Conference on Antimicrobial Agents and Chemotherapy, Boston.

20. Croci L, Trezzi M, Allegri MP, Carli T, Chigiotti S, et al. (2012) Pharmacokinetic and safety of raltegravir in pregnancy. Eur J Clin Pharmacol 68: 1231-1232.

21. Dickinson L, Khoo S, Back D (2010) Pharmacokinetics and drug-drug interactions of antiretrovirals: an update. Antiviral Res 85: 176-189. 
Citation: McLaughlin MM, Galal A, Ong J, Dinh M (2014) Use of Raltegravir in HIV-Infected Pregnant Women: A Case Series and Review of the Literature. J AIDS Clin Res 5: 386. doi:10.4172/2155-6113.1000386

Page 4 of 4

22. Else LJ, Taylor S, Back DJ, Khoo SH (2011) Pharmacokinetics of antiretroviral drugs in anatomical sanctuary sites: the male and female genital tract. Antivir Ther 16: 1149-1167.

23. Grinsztejn B, Nguyen BY, Katlama C, Gatell JM, Lazzarin A, et al. (2007) Safety and efficacy of the HIV-1 integrase inhibitor raltegravir (MK-0518) in treatment-experienced patients with multidrug-resistant virus: a phase II randomised controlled trial. Lancet 369: 1261-1269.

24. Cao R, Hu Y, Wang Y, Gurley EC, Studer EJ, et al. (2010) Prevention of HIV protease inhibitor-induced dysregulation of hepatic lipid metabolism by raltegravir via endoplasmic reticulum stress signaling pathways. J Pharmacol Exp Ther 334: 530-539.

25. Antiretroviral Pregnancy Registry Steering Committee (2013) Antiretroviral Pregnancy Registry International. Interim Report for 1 January 1989 through 31 July 2013. Wilmington, NC: Registry Coordinating Center. 